\title{
Gestão do controle de cães e cidade digital estratégica: caso de Curitiba
}

\author{
Beatriz Alcantara Castelo ${ }^{1}$ \\ Denis Alcides Rezende ${ }^{2}$ \\ Giovana Goretti Feijó de Almeida ${ }^{3}$
}

\begin{abstract}
Resumo
O aumento de cães em situação precária nas cidades e a ausência de legislações específicas desafiam as decisões da gestão municipal no meio urbano. É ainda um problema de saúde e políticas públicas que levam às reflexões sobre o desenvolvimento territorial-regional. O objetivo é analisar as estratégias municipais para gestão do controle de cães e suas relações com cidade digital estratégica. A metodologia da pesquisa enfatizou um estudo de caso em Curitiba, Paraná. É uma pesquisa qualitativa que se vale de um protocolo com 7 variáveis. Os resultados auferidos confirmaram a existência de legislação específica para a gestão de controle de cães no meio urbano, porém, ainda são insuficientes em relação ao número de cães abandonados e fiscais que realizam esse controle. A conclusão reitera a existência de relações entre gestão de controle de cães e cidade digital estratégica por meio de dois subprojetos, estratégias e tecnologia da informação. Ao mesmo tempo, a realidade curitibana revelou lacunas nos planos de governo vigentes em relação a animais domésticos abandonados na cidade. É um cenário que merece atenção, visto que esses animais fazem parte do cotidiano urbano e, se não for gerido adequadamente, pode causar problemas à população e, inclusive, problemas no desenvolvimento territorial-regional.
\end{abstract}

Palavras-Chave: Controle de cães; Estratégias municipais; Serviços públicos; Desenvolvimento Territorial; Cidade digital estratégica.

\section{Dog control management and strategic digital city: Curitiba case}

\begin{abstract}
The dogs increase in precarious situations in cities and the absence of relevant legislation challenge the municipal management decisions in the urban environment. It is also a health problem and public policies that lead to reflection on regional development. The objective is to analyze the municipal strategies for dog control management and its relations with strategic digital city. The research methodology emphasized a case study in Curitiba, Paraná. It is a qualitative research that uses a protocol with seven analyzed variables. The results obtained confirmed the existence of specific legislation for the dog control management in the urban environment, however, they are still insufficient in relation to the number of abandoned dogs and inspectors who perform this control. The conclusion reiterates the existence of relations between dog control management and strategic digital city through two subprojects, strategies and information technology. At the same time, Curitiba's reality revealed gaps in the government plans in place regarding abandoned domestic animals in the city. It is a scenario that deserves attention, since these animals are part of everyday urban life and, if not managed properly, can cause serious problems to the population and problems in territorial-regional development.
\end{abstract}

Keyword: Dog control; Municipal strategies; Public services; Territorial Development; Strategic digital city.

\footnotetext{
${ }^{1}$ Mestrado em Gestão Urbana (PPGTU-PUCPR). http://lattes.cnpq.br/9113477762658095 Email: biaac3@gmail.com

2 Doutorado em Alinhamento da Tecnologia da Informação a Negócios. Pós-doutorado em Pós-doutor em Strategic Digital City (DePaul University - Chicago-USA) e Pós-doutorado

em Administração Pública. Professor no Programa de Pós-Graduação em Gestão Urbana (PPGTU) da Pontifícia Universidade Católica do Paraná (PUCPR). https://orcid.org/0000-0002-3327-0424 Email; denis.rezende@pucpr.br

${ }^{3}$ Doutorado em Desenvolvimento Regional (UNISC). Pós-doutorado em Gestão Urbana/Cidade digital estratégica (PPGTU-PUCPR). Professora-visitante no Programa de Pós-Graduação em Gestão Urbana da PUCPR. http://orcid.org/0000-0003-0956-1341 Email:goretti.giovana@gmail.com
} 


\section{Introdução}

O aumento de cães em situação precária nas cidades e a ausência de legislações específicas desafiam as decisões da gestão municipal no meio urbano. É ainda um problema de saúde e políticas públicas que levam às reflexões sobre o desenvolvimento territorial-regional. Embora a população nas cidades seja estimada pelo número de seus residentes, há de ser levado em conta os animais domésticos no contexto urbano, em especial, os abandonados que circulam pelas ruas sem nenhum cuidado, muitas vezes, circulando entre uma cidade e outra. De cada 100 famílias brasileiras, 44 criam cães e apenas 36 famílias têm crianças de até doze anos de idade. Faz-se essa comparação, visto que os cães são associados com frequência às famílias que possuem crianças. Chama a atenção que esses números crescem à medida que se consideram outros tipos de animais domésticos. Os animais estão mais presentes no País do que os próprios jovens. Com a elevação do número de animais, percebeu-se igualmente um crescimento de casos de maus tratos e abandono. A interação homem-animal não é nenhuma novidade para as pessoas que moram nas áreas urbanas. Todavia, nem todas gostam de conviver ou manter relacionamentos amistosos com os animais (OMS, 2013; IBGE, 2013).

Incluem-se nessa discussão os casos em que ocorre a renúncia de bichos domésticos no meio urbano, concretizando-se em abandono ou maus tratos. Esse cenário pode causar uma superpopulação desses animais nas ruas que trazem consigo inúmeros transtornos. Por consequência, pode levar ao desequilíbrio, urbano e regional, ameaçando à saúde pública e desafiando às políticas públicas (SOUZA, 2014; MDR, 2020). O problema vai além do controle, incluindo resgate e monitoramento de animais domésticos circulantes nas cidades e regiões. Na Política Nacional de Desenvolvimento Regional (PNDR, 2020), encontra-se ênfase à promoção da qualidade de vida. Neste caso, dar a devida atenção aos animais domésticos que circulam no meio urbano, em especial aos abandonados, é uma forma de refletir sobre o desenvolvimento territorial-regional e à qualidade de vida dos cidadãos. Há de se levar em conta ainda que são elementos do contexto urbano que não compreendem fronteiras, circulando de um lugar para o outro, de uma cidade para outra, ou chegando a ir de uma região à outra. Assim, percebe-se que a gestão do controle de cães se insere também na reflexão do desenvolvimento territorialregional com destaque à gestão das cidades e ao papel dos atores sociais. O contexto territorialregional é abrangente e se refere às múltiplas dimensões, econômica, social, ambiental e física (PECQUER, 2005; SOUZA, 2014). 
Os problemas da pesquisa englobam: abandono de cães, transformando-os em vetores de doenças, tais como: toxoplasmose, raiva, sarnas, lavra migrans, entre outras (KIMURA, 2012); bem como o papel e a importância da intervenção do governo local e regional no sentido de realçar a qualidade de vida (LIMA, 2006). As doenças transmitidas por animais domésticos abandonados levaram a população urbana a implementar medidas para seu controle populacional, eliminando-os indiscriminadamente. Uma dessas determinações foi à extinção de cães sem restrições mais específicas, levando-os à morte em massa. Acreditava-se, na época que, ao adotar este critério, estar-se-ia a controlar as doenças que esses animais transmitiam às pessoas. Foi considerada ineficiente em meados da década de 1990 (OMS, 2013). O aumento da obtenção de cães e gatos como animais de companhia combinado a utilização de áreas públicas tem contribuído para a elevação do número de pessoas expostas ao risco de contrair infecções por parasitas transmitidos por animais de estimação. Pelo menos $60 \%$ das doenças infecciosas comprometem a saúde dos seres humanos e, aproximadamente, $75 \%$ das doenças novas ou emergentes em humanos, em todo o mundo, são consideradas zoonoses (DOMINGUES, 2015). Com o aumento da população dos animais, observou-se certa elevação no número de maus tratos com os mesmos, especialmente, cães e gatos, desencadeando movimentos, campanhas e ações judiciais para suas preservações. A tutela jurídica dos animais está presente na Constituição Brasileira (BRASIL, 1998) com a finalidade de possibilitar a convivência entre animais e pessoas. A ausência de Órgãos ou Entidades governamentais, ou filantrópicas que possam ajudar na gestão deste controle acaba por prejudicá-los mais do que os ajudar. Segundo a Sociedade Mundial de Proteção Animal (2017) se estima que 75\% dos cães do mundo vivem nas ruas, sem lar, abandonados à própria sorte. À vista do exposto, percebe-se certa ingerência desses animais por parte da sociedade e, principalmente da gestão pública. Destaca-se que essa negligência implica em impactos tanto para a saúde pública quanto para o bem-estar animal (LIMA, 2006; SOUZA, 2014; WSPA, 2018).

A questão-problema abarca: quais as estratégias municipais da gestão do controle de cães em Curitiba e suas relações com cidade digital estratégica?

O objetivo é analisar as estratégias municipais da gestão do controle de cães em Curitiba e suas relações com cidade digital estratégica. Para isso se faz necessário abordar o conceito de cidade digital estratégica e três de seus subprojetos: estratégias, serviços públicos e tecnologia da informação; verificar quais estratégias municipais Curitiba utiliza no controle de cães 
abandonados na cidade e; identificar a existência de leis ou projetos de leis existentes para o controle populacional canino.

As justificativas da pesquisa se estendem ao uso de animais na sociedade, como: força de trabalho, alimentação, lazer, companhia, terapia e experimentação científica (DI NAPOLI; 2013). Ainda, todo cidadão possui o direito de conviver com animais domésticos, desde que se considerem as normas de convivência nos ambientes residenciais e públicos. $\mathrm{O}$ vínculo afetivo pode resultar em benefícios, como: redução dos níveis de ansiedade nos tutores, retardamento do agravamento ou progressão de doenças relacionadas ao estresse, alergias respiratórias e cutâneas, estresse e problemas cardíacos ou de pressão (SOUZA, 2014; DOMINGUES, 2015). A presença dos cães nos lares pode auxiliar na diminuição do sedentarismo e aumento da sociabilidade, refletindo na saúde física e mental dos seres humanos. Esta melhoria pode contribuir para uma sociedade, cidade e região com maior qualidade de vida para seus cidadãos. Diante do exposto, refletir sobre a gestão do controle, resgate e monitoramento de animais urbanos possibilita compreender as dinâmicas territoriais urbanas. Ao fazê-lo, percebe-se a complexidade do desenvolvimento territorial-urbano, na qual a população canina está inserida (LEVINE, 2013; SOUZA, 2014).

\section{Fundamentação Teórica}

\subsection{Gestão do controle de cães}

\subsubsection{Cães}

O surgimento evolutivo dos cães advém do cão selvagem e cão doméstico (Canis lupus familiaris), sendo ainda um tema controverso. A situação decorre das diversas teorias sobre adestramento e questões morfológicas, além da diversidade de raças caninas existentes. A discussão surge por não se ter certeza de onde, quando ou como esses animais passaram a ser domesticados. Sabe-se apenas que, historicamente, o lobo cinzento (Canis lupus) é um de seus principais ancestrais (WANG et al., 2015). Na literatura há duas versões difundidas. Uma em que os cães primitivos foram domesticados a partir de seus ancestrais selvagens, os lobos cinzentos. A outra versão, considerada um segundo estágio evolutivo, diz que as formas primitivas derivadas desses cães selvagens foram selecionadas para desenvolver raças de cães com habilidades especializadas. Seria um cenário decorrente da necessidade das pessoas que criaram 
raças específicas, chegando aos cães que se tem nas cidades contemporâneas (COPPINGER; COPPINGER, 2001; WANG et al., 2015; PENNISI, 2017). Destaca-se que a gestão do controle desses animais é dificultada pela sua constante locomoção, dificultando a estimativa real da população canina (WHO, 1992; MANUAL TÉCNICO DO INSTITUTO PASTEUR, 2000). Assim, os cães podem se locomoverem tanto numa mesma cidade como numa mesma região. O vínculo entre os animais urbanos e o desenvolvimento territorial-urbano adentra preocupações territoriais e regionais, podendo ser um entrave em relação à qualidade de vida da população brasileira (BELLINGIERI, 2017).

\subsubsection{Gestão de animais urbanos}

Em 1992 foi publicado um informe técnico que listava os métodos aceitáveis para o controle da população de animais, baseando-se em: restrição de movimentos; programas educativos para guarda responsável; controle de habitat e regulação da reprodução (OMS, 1992). Porém, para que tais medidas funcionassem de modo efetivo, fez-se necessário igualmente o controle do número de criadouros e sua comercialização. Até 2007, os municípios brasileiros, inclusive Curitiba usavam a captura e o extermínio dos animais, principalmente, cães e gatos (PORTAL, 2018). Era a forma de controle populacional na época, sendo um método utilizado indiscriminada e sistemicamente. Julgava-se ser essa a forma mais eficaz para evitar a reprodução e transmissão de doenças, pensamento defendido pela sociedade na década de 1990. Existia o entendimento de que era necessária a retirada (extermínio) desses animais da rua para que pudesse ser feito o manejo adequado dessas populações e o devido controle de doenças transmitidas, principalmente, a raiva (OMS, 1992; PORTAL, 2018).

Ao longo do tempo esses métodos foram considerados ineficazes devido ao seu potencial de reprodução e mobilidade. A falta de controle gerou problemas tanto para a saúde pública como para o bem-estar dos próprios animais (RDPAC, 2009). Para se ter uma ideia, uma cadela ou gata, saudável e em condições para reprodução pode gerar, em um período de vida médio (10 anos), 108 filhotes em média. A estimativa deriva da suposição de que pelo menos metade nasceria fêmeas. Se isso acontecesse se teria 5.832 cães ou gatos a mais circulando pela cidade (SOUZA, 2014). Enfatiza-se que o convívio com os animais requer cuidados que, se ignorados, podem trazer consequências indesejadas à sociedade, como, por exemplo as doenças. Nesse sentido, citam-se: raiva, leishmaniose e outras, além de agressões envolvendo homem-animal, 
acidentes de trânsito, poluição ambiental por dejetos e dispersão de lixo (SOUZA, 2014; OMS, 2017).

A gestão do controle de animais que convivem no contexto urbano-regional é necessária devido às doenças que transmitem na sociedade, tais como: morcegos, ratos, cobras, aranhas, pombos, cavalos, gatos, cães e outros. Todas as espécies de animais, domésticos ou não, devem ser controladas por um setor responsável. Em geral, este papel é desempenhado pelo Centro de Controle de Zoonoses (CCZ) vinculado à Secretaria Municipal de Saúde (SMS) ou Secretaria Municipal do Meio Ambiente (SMMA). Suas principais funções estão relacionadas ao planejamento, administração e execução de programas de monitoramento, além da vigilância e controle ambiental e população da fauna urbana (RDPAC, 2009; BRASIL, 2016). As políticas públicas orientam o território no que tange ao planejamento local e regional. Uma dessas capacidades pode remeter ao controle de elementos que fazem parte do contexto urbano, como é o caso dos cães abandonados. O aumento descontrolado da população canina pode ser tornar um sério problema urbano se não for controlado e gerido adequadamente. Trata-se de uma questão mais complexa do que a preservação de animais, adentrando o bem-estar e melhores condições de vida das pessoas em um dado território e sua região (SANT'ANNA; OLIVEIRA, 2019).

\subsubsection{Estratégias na gestão do controle de cães}

As estratégias podem diferir de município para município e região para região, mas de acordo com a Secretaria de Vigilância e Saúde (SVS, 2017), existem 11 estratégias para promoção e proteção da saúde coletiva, cuja função fundamental na gestão de animais tem se concentrado na disseminação de conhecimento e informação para a população em geral. As referidas estratégias são: participação comunitária; visitas domiciliares; correspondência; transversalidade com as equipes de atenção básica; participação nos conselhos municipais de saúde; palestras; atividades lúdicas (músicas, peças teatrais, gincanas, jogos, entre outros); eventos em espaços públicos; atividades em escolas; meios de comunicação e transmissão para multiplicação de conhecimento (BRASIL, 2008; 2016). O objetivo principal das estratégias tem sido "[...] possibilitar que a informação científica seja repassada de forma compreensível, considerando o contexto social, histórico e cultural da população-alvo" (BRASIL, 2008, p. 89). 


\subsection{Cidade digital estratégica}

Os planejamentos e planos municipais devem ser realizados com a participação de cidadãos e servidores municipais. Neste sentido, Rezende (2012) criou o conceito de cidade digital estratégica a partir da aplicação dos recursos da tecnologia da informação na gestão do município e também na disponibilização de informações e de serviços aos munícipes ou cidadãos. Para que a cidade digital estratégica exerça sua finalidade deve ser composta por quatro subprojetos: estratégias municipais; informações municipais; serviços públicos municipais; e recursos da tecnologia de informação. É um projeto de cidade que tem como base as estratégias para atender seus objetivos municipais (REZENDE, 2012; 2018).

\subsubsection{Estratégias municipais}

A palavra estratégia diz respeito ao preparo da organização para enfrentar um ambiente agressivo. Utilizam-se competências, recursos e qualificações para que se alcancem os fins almejados (CAMARGOS; DIAS, 2003; CASTELO, 2008). Entendem-se as estratégias (MINTZBERG et al., 2014) também no âmbito do município como meios para alcançar os objetivos municipais. O município pode ser entendido como um organismo complexo e dinâmico que está sempre se modificando. Caracteriza-se por: diversidades, múltiplos contrastes e divergentes interesses, o que traz dificuldades aos gestores municipais (REZENDE, 2012).

O planejamento estratégico municipal é um instrumento utilizado na gestão de uma cidade (PFEIFFER, 2000). Pode ser entendido como processo de longo prazo em que se estabelece aonde e como se quer chegar (MORAIS, 2005), bem como parte de funções interligadas da administração (planejamento, organização, direção e controle) presentes em um ciclo (REZENDE, 2012). Podem ser resumidas como atividades que realizam os objetivos municipais, sendo as ações municipais o detalhamento das estratégias (REZENDE; CASTOR, 2006).

\subsubsection{Informações municipais}

As informações municipais são fundamentais para a gestão municipal, incluindo tomadas de decisões, funcionamento dos espaços urbanos e relações sociais (LEMOS, 2007). A informação é reutilizável, sendo seu valor mensurado pelo usuário que a coleta (MCGEE; PRUSAK, 2002). Ao 
mesmo tempo, podem ser vistas como um conjunto de componentes inter-relacionados que trabalham juntos (LAUDON; LAUDON, 1999; CAUTELA; POLLONI, 2001).

A informação é um dado tratado com os recursos computacionais de forma personalizada, cuja finalidade é trazer benefícios para a instituição, tais como: qualidade de trabalho, rentabilidade, produtividade e competitividade. Assim, as informações, sejam empresariais ou organizacionais, tornam-se um instrumento que contribui com o planejamento, desenvolvimento ou aquisição de sistemas de informação (REZENDE, 2005).

\subsubsection{Serviços públicos municipais por meio da tecnologia da informação}

Serviço público é toda atividade de oferecimento de utilidade ou comodidade pública (MUKAI, 1995). O conceito de serviço público não é uniforme, referindo-se àquele prestado pela administração pública. São exemplos de serviços públicos: educação pública, polícia, saúde pública, transporte público e telecomunicações (MEIRELLES, 2013).

Os serviços públicos são atividades desenvolvidas de forma a gerar bens não tangíveis para os cidadãos (REZENDE, 2011). Remetem à serviços que podem ser considerados como um fator estratégico na competitividade das cidades. O ponto central dessa oferta coletiva é a satisfação das necessidades básicas da população, portanto, tem que partir da demanda da população para serem considerados úteis em uma dada realidade socioespacial (CASTELLS; BORJA, 1996).

Os serviços devem ser disponibilizados por meio da tecnologia da informação, que são recursos computacionais compostos por hardware, software, telecomunicações e gestão de dados e informações (REZENDE, 2012).

\section{Metodologia da Pesquisa}

Utilizou-se do método de estudo de caso para evidenciar o fenômeno de controle de gestão de cães no ambiente urbano (YIN, 2015). É uma pesquisa qualitativa de caráter aplicado que se vale da pesquisa bibliográfica para aprofundar os temas centrais propostos no estudo. Para a coleta de dados foram utilizadas técnicas qualitativas e quantitativas (MICHEL, 2015; SAMPIERI; COLLADO; LÚCIO, 2013). 
A abrangência da pesquisa se concentrou na cidade de Curitiba, Paraná, Brasil. A escolha se deu devido a cidade possuir o maior número de animais no Brasil (IBGE, 2013; OLIVEIRA; ALMEIDA; BARBOSA, 2013). O município de Curitiba apresenta uma área territorial de 434,89 km² com uma população estimada em 1.933.105 habitantes (IBGE, 2019).

A unidade de observação se concentrou na procedência de dados secundários das leis municipais de gestão do controle de animais domésticos de Curitiba, em especial, os cães; incluindo documentos online públicos disponíveis no site da Secretaria Municipal do Meio Ambiente (2018). Entre esses documentos, podem ser citados: Política Nacional de Desenvolvimento Regional do Brasil; Manual de vigilância, prevenção e controle de zoonoses; Manual de vigilância e controle da peste; Resumo executivo do projeto rede de defesa e proteção animal da cidade de Curitiba e Constituição do Brasil. Além destes, buscou-se, também, nos seguintes sites eletrônicos (2018): ABRACHIP, Ministério da Saúde do Brasil, IBGE, Ministério do Desenvolvimento Regional do Brasil, Portal da Prefeitura Municipal de Curitiba, Rede de Proteção Animal de Curitiba, Rede de Defesa e Proteção Animal da Cidade de Curitiba, World Animal Protection, World Health Organization e Canal 156 (MARCONI; LAKATOS, 2017).

A pesquisa abrangeu as fases: 1) preparar pesquisa; 2) coletar dados e; 3) analisar dados (MARCONI; LAKATOS, 2017). Utilizou-se um protocolo de pesquisa com sete variáveis analisadas (YIN, 2015): estratégias na gestão no controle da gestão de cães, investimento no controle de animais urbanos, leis municipais, estratégias para a cidade, informações sobre a cidade, serviços públicos municipais e, relações entre os constructos investigados. A pesquisa foi realizada no período de outubro de 2017 a junho de 2018, sendo atualizada em março de 2020.

\section{Análises da gestão de controle de cães}

\subsection{Análises das Estratégias municipais no controle da gestão de cães}

\subsubsection{Análise da população canina em Curitiba}

Os animais domésticos já são mais presentes do que as crianças (zero - quatorze anos) no Brasil. Em 2013, os números chegaram a 44,9 milhões de crianças e mais de 132 milhões de animais urbanos. São cerca de 50 milhões de cães e 20 milhões de gatos, considerando o Paraná como o estado com o maior número de animais no País. Composta por uma população de 1.908,359 milhões habitantes (IBGE, 2017) a capital paranaense possui, aproximadamente, 380 
mil cães que circulam na cidade. A estimativa é de que há 1 cão para cada 5 pessoas que vivem no meio urbano. Deste universo, $10 \%$ são de cães abandonados, somando-se pouco mais de 38 cães sem lar. Da população residente em Curitiba se encontrou que 342,831 mil pessoas recebem auxilio do governo, por meio do Programa Bolsa Família. Calcula-se que 68,567 mil dessas pessoas possuem cães, destacando que, além dos 38,167 mil cães abandonados, existem outros 68.567 que podem estar em condições precárias longe do ideal para o convívio homem-animal (IBGE, 2017; PORTAL, 2018).

O crescente número de animais abandonados nas cidades pode ser sido originado pela falta de conhecimento na criação de animais domésticos. Assim, a precariedade de informações para a população poderia ser uma das principais causas de seu abandono. Essa situação pode ser considerada, como mencionado por Bellingieri (2017), um entrave para o bem-estar da sociedade, já que os animais domésticos estão inclusos na vida em sociedade. De um total de 381,671 mil cães, presume-se que 106,734 mil vivem em condições precárias ou de abandono, gerando uma situação problemática para o poder público tanto em âmbito local quanto regional. Desta forma, torna-se um problema tanto de saúde pública quanto de políticas públicas que podem, no que lhe concerne, interferir na qualidade de vida urbana.

\subsubsection{Análise do tipo de gestão no controle de cães no meio urbano}

O controle de animais no meio urbano é prioritariamente de responsabilidade da Secretaria Municipal de Meio Ambiente (SMMA), Centro de Controle de Zoonoses (CCZ) e Secretaria Municipal de Saúde (SMS). Além desses Órgãos, a prefeitura de Curitiba ainda possui o Programa Rede de Proteção Animal (RDPAC, 2009) constituído por agentes locais. Esses agentes são pessoas responsáveis pelo manejo populacional de animais domésticos que habitam em áreas urbanas. Igualmente são considerados os responsáveis por informar e educar a população em situações normais ou em epidemias causadas pelos próprios animais. A RDPA é um Programa da Prefeitura de Curitiba que abrange: setor público e privado, e o terceiro setor (sociedade civil com e sem fins lucrativos). A junção desses três agentes busca melhores condições para a fauna urbana da qual os cães fazem parte. É oferecido o Sistema de Cadastramento e de Identificação Animal (SIA) que utiliza a implantação de microchips nos animais domésticos, especificamente, cães e gatos. Contudo, o poder público não é o único responsável por esse controle. Existem organizações não governamentais (ONGs) que resgatam 
animais abandonados, castrando-os e procurando novos lares para que possam conviver com os seres humanos. Em geral, as ONGs sobrevivem de doações da sociedade civil e parcerias públicoprivadas. Muitas vezes, o governo entra em contato com as ONGs para realizar eventos de vacinação, castração ou, até mesmo, adoção de animais.

Além da castração, investimentos realizados pelos setores, público e privado, são utilizados com frequência, como a implantação de microchip no controle e coleta de informações. A estratégia agrega informações de seus tutores, sendo considerada uma medida preventiva para evitar o abandono. Outro serviço que está sendo implementado pelo setor privado é a certidão de nascimento animal. Nela ficam registradas as principais características dos animais, podendo ser encontrado este serviço em algumas cidades do Brasil, tais como: João Pessoa-PB, Curitiba-PR e São Paulo-SP. Enfatiza-se que é um serviço realizado em cartórios específicos, sendo uma iniciativa do poder privado.

A parceria público-privada se apresenta como uma solução de menor custo para os governos. Pode-se dizer que resulta em maior eficiência, pois beneficia um número maior de pessoas. Quanto ao poder público, "[...] os recursos empregados para a consolidação do programa são procedentes do Fundo Municipal do Meio Ambiente, totalizando o montante de $R \$$ 2,5 (dois milhões e meio de reais) aplicados nas cirurgias, no microchip e em trabalhos de educação para a guarda responsável". A parceria entre os atores sociais pode levar às políticas públicas que tratem também do destino e controle de animais domésticos. Ao fazê-lo, remetese aos postulados de Sant'Anna e Oliveira (2019) no que tange a território orientado para planejamentos eficazes, tanto em escala local quanto regional.

\subsubsection{Análise das Leis municipais que regulam o controle de animais}

Entre as leis municipais que regulam os animais, destacam-se treze: Lei no 7.409/1989, Lei no 7.833/1991, Decreto no 643/2001, Lei no 9.493/1999, Decreto no 642/2001, Lei no 12.467/2007, Lei oㅗ 12.59/2008, Lei no 13.241/2009, Lei № 13.558/2010, Lei no 13.908/2011, Lei no 13.914/2011, Lei no 14.741/2015, Decreto no 643/2015. Percebe-se que mesmo com a existência de leis para a proteção, regulamentação e controle de animais no meio urbano, ainda há carência de fiscalização e recursos. A baixa quantidade de pessoas responsáveis pela fiscalização é notória devido ao número dos animais que sofrem de maus tratos, gerando inúmeras denúncias recebidas pelo canal 156. Quando se tratam de recursos, pode-se citar a 
quantidade de castrações (insuficientes) ofertadas e comparadas com a demanda necessária. Desde 2017, a OMS tem alertado quanto as consequências indesejadas que os animais domésticos podem trazer à vida em sociedade, enfatizando cuidados necessários, especialmente no meio urbano. Isso requer pensar em legislações, fiscalização e recursos necessários para o convívio saudável entre animais e seres humanos nas cidades.

\subsection{Análises dos subprojetos da cidade digital estratégica}

\subsubsection{Análise das estratégias da cidade na gestão do controle de cães}

Curitiba apresenta um programa próprio para fazer o controle dos animais no meio urbano, o RDPAC. É um meio pelo qual são promovidas ações para melhorar as condições de vida dos animais na cidade. Disponibiliza castração sem custos para as pessoas filiadas aos programas sociais, como: Armazém da Família; Bolsa Família; ONG Proteção Animal ou Protetor Independente. Oferece sistemas de cadastro e identificação animais (SIA), utilizando-se de microchips e de um programa de guarda responsável que informa a população local sobre os cuidados necessários com o animal. Segundo a SMMA (2018), o objetivo da Rede (2018) “[...] é estabelecer medidas para atuar na conservação ambiental, em especial, na defesa, proteção e no controle de populações para atingir o equilíbrio ambiental". Desta forma, pode ser possibilitada a convivência saudável entre pessoas e animais em um mesmo ambiente.

A prefeitura dispõe, por meio do contato com a RDPA, de um canal para denúncias sobre maus tratos dos animais. Em média, chega-se a mais de cem denúncias por dia (canal 156, acesso online ou por telefone) referente ao recolhimento seletivo de animais ferozes e cães de grande porte. Convém destacar que o recolhimento indiscriminado foi interrompido em 2005, assim como o canil público, alegando que eram medidas que estimulavam o abandono de animais.

À vista do exposto, as principais estratégias para a gestão no controle de animais em Curitiba se concentram em: castração gratuita, implantação de microchip, campanhas de vacinação, recolhimento de animais abandonados, repreensão de maus tratos animais e divulgação de informações sobre a guarda responsável. É válido destacar que, se o Planejamento Estratégico Municipal é um documento que auxilia em tornar a gestão de uma cidade mais efetiva (PFEIFFER, 2000), então, pode-se dizer que é necessário incluir a discussão da gestão de controle de cães nesse debate. 


\subsubsection{Análise dos serviços públicos no controle de cães}

O serviço municipal online ofertado pela Prefeitura de Curitiba é o cadastro de animal, cão ou gato, utilizando a aba de cadastro, localizada no site da RDPAC. Para a realização do cadastro o dono deve informar seus dados pessoais (CPF e RG ou o SIC) para somente depois cadastrar o animal como seu pertencente. Após a conclusão do cadastro, o dono do animal deve ir até a Rua da Cidadania para comprovar as informações, momento em que estará apto a utilizar algum dos serviços ofertados pela Prefeitura Municipal. Trata-se, portanto, de um serviço público que, como mencionado por Mukai (1995), oferece uma atividade de utilidade pública.

As informações sobre a agenda dos eventos locais podem ser acessadas pelo site, além de subsídios sobre a guarda responsável, adoção, dicas de cuidados, parceiros e legislação que regulam os animais. Entretanto, para a campanha de castração, é necessário agendamento por telefone. Após a validação dos dados em uma das unidades responsáveis para a implantação do microchip é realizado um cadastro prévio pelo site ou na própria RDPA. Caso o animal seja microchipado em outro lugar, o número do chip e seus dados devem ser inseridos no referido site para que os parceiros autorizados pela prefeitura os confirmem, facilitando a busca e a identificação do animal. Outro serviço é o canal 156 utilizado para denúncia de maus tratos de animais, orientações para combates de pragas urbanas e desratização em locais públicos. O canal pode ser acessado via online ou por telefone. As informações oriundas da agenda de eventos locais servem tanto para os cidadãos quanto à tomada de decisão da gestão local. Nesse sentido, retoma-se a fala de Lemos (2007), destacando que as decisões dos gestores públicos influenciam nos espaços urbanos e nas relações sociais.

Os principais serviços online existentes para os animais são: informações sobre eventos beneficentes, arrecadação de produtos e feiras de adoção de animais. Além dos eventos citados se podem encontrar informações sobre cadastramento de animais, oferta de serviços públicos ou privados (vacinação e castração), aplicação de microchip, dicas de cuidados, legislação vigente, informações sobre apreensão de animais nocivos ou abandonados no meio urbano e canal 156 para denúncia de maus tratos.

Apesar da disponibilização desses serviços serem úteis para as pessoas que possuem animais, sua divulgação ainda é insuficiente para o conhecimento de boa parte da população curitibana. Assim, embora seja um ponto positivo a existência e o acesso a esses serviços, 
observa-se falta de divulgação. De acordo com a ABRACHIP (2017), no Brasil existem 132,4 milhões de animais domésticos que receberam chips. As informações coletadas por esses chips revelam a existência de 323,134 mil animais. É um número que apesar de alto, ainda é inferior ao número de animais abandonados no meio urbano. Estima-se que se forem contabilizados apenas cães e gatos abandonados, há aproximadamente 90 milhões.

Este número ainda é considerado inferior ao número de animais castrados nas cidades. Nos centros de controle animal, presume-se que somente entre $10 \%-20 \%$ dos animais que residem no meio urbano são castrados. A ausência do chip ou outro método de identificação dificultam a sua localização em casos de fuga. Igualmente ainda atrapalha a intimação do dono em caso de abandono ou maus tratos, aumentando a possibilidade da reprodução descontrolada e, por consequência, a ampliação e propagação de doenças. Esta situação pode gerar, por exemplo, um problema de saúde pública.

\subsection{Análise das relações entre gestão de controle de cães e cidade digital estratégica}

No que tange aos resultados auferidos, percebe-se que há relações entre gestão no controle de cães em Curitiba com a cidade digital estratégica. Em especial essas relações se dão a partir de 03 subprojetos: estratégias da cidade, serviços públicos e informações municipais. Em todos se encontrou associação com o manejo populacional dos cães abandonados ou que se encontram em situações precárias. A cidade digital estratégica é um projeto social que, conforme destacado por Rezende (2018), busca atender estrategicamente os objetivos da cidade. Assim, se um dos objetivos da cidade é o controle de cães é pertinente sua inserção nos subprojetos da cidade digital estratégica.

Quando se relacionam número de cães abandonados em Curitiba $(38,167$ mil) com a quantidade de castrações realizadas pelo referido serviço público se percebe que o mesmo é insuficiente. Cita-se a castração do animal por essa ser a principal ação para o controle do número de cães abandonados, disponibilizadas pela prefeitura em 2017 (15 mil). Este número é dividido ainda entre cães e gatos, e os animais que pertencem à população carente $(68,567$ animais abandonados devem ser resgatados por ONGs ou por tutores voluntários para que possam ser castrados e doados posteriormente).

Para a Secretaria Municipal da Saúde de Curitiba (2018) foi autorizado $\mathrm{R} \$ 1,7$ bilhões e, por outro lado, $\mathrm{R} \$ 2,5$ milhões foram destinados ao Fundo Municipal do Meio Ambiente para o 
setor responsável pela gestão do controle de animais. Ao comparar ambos os números são notórios a diferença de investimento entre as partes. Assim, pode-se considerar insuficiente esse investimento quando os animais domésticos criados pelos cidadãos não são considerados também um problema de políticas públicas. No entanto, mesmo com o investimento mencionado, ainda é escasso o recurso destinado à gestão do controle de cães, não pelo valor do investimento, mas pela quantidade de animais presentes no meio urbano.

Com o crescente aumento da quantidade dos cães nas cidades foram criadas estratégias para fazer seu manejo. Apesar da existência de táticas ainda é difícil fazer o controle desses animais devido à alta taxa de reprodução e fácil deslocamento, principalmente, daqueles que não tem tutores. Embora as estratégias sejam de fácil acesso pela população - via internet ou meio físico - é necessária à validação dos dados em local físico, o que revela que o controle da prefeitura de Curitiba ainda é precário.

No que se refere ao animal no meio urbano, existem leis específicas para seu controle, segurança e bem-estar. Apesar da existência dessas leis e dos canais para denúncias, a quantidade de pessoas responsáveis por fazer essa verificação é pequena em relação à demanda da solicitação, tornando-a falha na prática. Além das leis para a proteção dos animais, existem outras que facilitam seu traslado no meio urbano. Como os animais são considerados parte das famílias, a maioria das pessoas que possuem animais preferem frequentar locais em que estes sejam bem-vindos. A situação gerou uma flexibilização das regras nos lugares públicos (shoppings, restaurantes e até hospitais) para a adaptação e recebimento dos pets. Esse cenário é dirigido ao que Rezende (2011) menciona sobre a inclusão de atividades que geram bens tangíveis aos cidadãos. Ao mesmo tempo, é o que Castells e Borja (1996) se referem como fator estratégico que influencia na competitividade das cidades.

\section{Considerações finais}

O aumento de cães em situação precária nas cidades e a ausência de legislações específicas desafiam as decisões da gestão municipal no meio urbano. Trata-se de um problema de saúde e políticas públicas que levam às reflexões sobre o desenvolvimento territorial-regional. Apesar da existência de leis específicas no tocante à gestão do controle de cães em Curitiba ainda se questiona o controle desses animais devido à constante migração dos que não possuem um lar fixo ou vivem soltos nas ruas. Há de se considerar a baixa quantidade de pessoas designadas 
para fazer o monitoramento e fiscalização de cães na cidade. São efetivos os recursos digitais disponibilizados para ajudar a população mais carente a obter informações sobre os serviços oferecidos pelo governo, como a castração, vacinação ou a aplicação de microchip. Para a obtenção dos serviços oferecidos aos cidadãos é necessário que se tenha a inscrição em algum programa de auxílio municipal, bem como, registro por meio do site para, posteriormente, validar ou cadastrar direto seus dados em locais designados. Assim, percebe-se que a necessidade da comprovação da autenticidade dos dados diminui em parte a agilidade do Programa, todavia, evita a falsificação por terceiros, pois a castração gratuita só será destinada ao restante da população caso sobrem vagas.

O objetivo de analisar as relações entre gestão do controle de cães e cidade digital estratégico foi atingido. Permitiu visualizar a existência de estratégias, serviços públicos e informações municipais específicas para a gestão de cães abandonados. É um panorama que se não for controlado com a devida atenção pode se tornar um sério problema de políticas e saúde públicas, tanto local quanto regional. Pode-se evidenciar as relações entre os constructos analisados, sendo pertinente sua discussão no contexto do planejamento urbano e desenvolvimento regional.

Os resultados auferidos comprovaram que apesar dos serviços ofertados pela prefeitura, os números ainda são menores do que o necessário. Praticamente 15 mil castrações não contemplaram nem a metade dos 106,734 cães existentes em situação precária ou de abandono em 2018. O cenário é preocupante no que se refere à saúde pública, demandando políticas públicas e legislações eficazes no controle deste problema urbano. Embora existam estratégias elencadas para a gestão no controle de cães, estas ainda são minguadas para um controle mais efetivo. Alguns dos motivos desta insuficiência se referem à facilidade do deslocamento dos cães abandonados, baixa quantidade de pessoas disponíveis para a fiscalização e conscientização da população sobre os animais domésticos. Embora os microchips sejam um dispositivo de grande potencial para o controle animal, sua abrangência poderia aumentar se possuíssem GPS para o rastreio. Esses aparelhos funcionam como uma medida preventiva contra o abandono, porém, um aspecto negativo é que eles não possuem um prazo de validade, continuando a contabilizar os animais mesmo após sua morte.

As contribuições da pesquisa sustentam as relações entre os constructos investigados no que se refere à gestão no controle de cães, em Curitiba-PR. Revela lacunas nos serviços públicos locais e nas estratégias municipais, sendo uma oportunidade para se ampliar a saúde pública da 
cidade e região. Em termos de avanço do conhecimento científico é um tema pouco explorado que vêm ganhando espaço na medida em que a quantidade de animais abandonados nas cidades aumenta. No que se refere ao grupo de estudos sobre cidade digital estratégica é uma ocasião favorável para discussões abrangentes, como a gestão de controle de cães no meio urbano e regiões. Expõe as formas que a sociedade tem encontrado para resolver seus problemas coletivos, como o uso de microchip em animais domésticos. No entanto, evidencia que somente seu uso é insuficiente, podendo ser inserida a tecnologia de rastreamento de GPS com prazo de validade definido, facilitando o controle dos animais cadastrados. O desenvolvimento territorial é entendido como um processo pelo qual a geografia dos territórios habitados pelas sociedades humanas é progressivamente transformada. Envolve componentes físicos (infraestruturas, paisagens rurais e urbanas, etc.), mas também a estrutura territorial ou o padrão de povoamento, isto é, a distribuição geográfica da população e das atividades humanas, em particular a dimensão das cidades e as relações que se estabelecem entre elas.

Quanto às limitações da pesquisa se destaca que o estudo realizado se dirigiu apenas a um caso, o da cidade de Curitiba. Assim, não pode ser generalizado para outras realidades. Salienta-se que nem todos os municípios apresentam as mesmas estratégias para a gestão do controle de cães e que os números desses animais tiveram que ser aproximados devido aos números disponíveis pelo IBGE e Prefeitura Municipal.

Ao relacionar a população de Curitiba com a população de animais domésticos, observouse a existência de mais de 38 mil cães abandonados na cidade. Isso se refere ao dobro das castrações oferecidas pela Prefeitura Municipal. A gestão do controle de cães é um desafio diário para seus tutores e igualmente para o poder público, responsável pela sua gestão. O desafio se concentra no equilíbrio de uma melhor qualidade de vida entre habitantes e animais urbanos, sendo uma realidade que já faz parte do cotidiano dos cidadãos, tanto local quanto regional. O planejamento urbano ancorado em políticas públicas efetivas pode orientar o desenvolvimento territorial-regional de forma a gerar bem-estar, segurança e qualidade de vida aos cidadãos. Para isso, todos os elementos que contemplam o meio urbano precisam ser considerados, sendo os cães abandonados um deles. Trata-se de refletir sobre um cenário em que animais fazem parte do cotidiano urbano e, se não for gerido adequadamente, pode causar problemas à população e, inclusive, problemas no desenvolvimento territorial-regional. 


\section{Referências}

ABRACHIP. Site institucional da Abrachip banco de dados de microchips em animais. http://www.abrachip.com.br. Acesso em: 12 abr. 2017.

BELLINGIERI, J. C. Teorias do desenvolvimento regional e local: uma revisão bibliográfica. RDE, v.2, n.37, 2017.

BRASIL. Constituição Federal. São Paulo: Revista dos Tribunais, 1998.

BRASIL. Lei no 9.605, de 12 de fevereiro de 1998. Diário Oficial, Brasília, 19 jul. 2000a. http://www.planalto.gov.br/ccivil_03/leis/L9605.htm. Acesso em: 19 abr. 2017.

BRASIL. Lei no 11.126, de 27 de junho de 2005. Diário Oficial, Brasília, 19 jul. 2000b. http://www.planalto.gov.br/ccivil_03/_Ato2004-2006/2005/Lei/L11126.htm. Acesso em: 19 abr. 2018.

BRASIL. Ministério da Saúde. Secretaria de Vigilância em Saúde. Departamento de Vigilância das Doenças Transmissíveis. Manual de vigilância, prevenção e controle de zoonoses: normas técnicas e operacionais [recurso eletrônico] / Ministério da Saúde, Secretaria de Vigilância em Saúde, Departamento de Vigilância das Doenças Transmissíveis. Brasília: Ministério da Saúde, 2016.

BRASIL. Site Institucional do Ministério da Saúde. Secretaria de Vigilância em Saúde. Departamento de Vigilância Epidemiológica. Manual de vigilância e controle da peste / Ministério da Saúde, Secretaria de Vigilância em Saúde, Departamento de Vigilância Epidemiológica. Brasília: Ministério da Saúde, 2008.

CAMARGOS, M. A.; DIAS, A. T. Estratégia, administração estratégica e estratégia corporativa: uma síntese teórica. Caderno de Pesquisas em Administração, v.10, n.1, p.27-39, 2003.

CASTELO, L. A. Avaliação das ações implementadas nas unidades operacionais do instituto CENTEC como forma de viabilizar o planejamento estratégico: análise da mesorregião do Jaguaribe-Ce. 2008. Dissertação (Mestrando em Engenharia de Produção), Universidade Federal da Paraíba, Paraíba, 2008.

COPPINGER, R.; COPPINGER, L. Dogs: a startling new understanding of canine origin, behavior and evolution. New York: Scribner, 2001.

DOMINGUES, L. R. et al. Responsible pet animal guardianship in the urban area of the municipality of Pelotas in the state of Rio Grande do Sul, Brazil. Ciênc. Saúde Coletiva, Rio de Janeiro, v. 20, n. 1, p. 185-192, 2015. Acesso em: 20 jun. 2017.

IBGE. Site Institucional do Instituto Brasileiro de Geografia e Estatística. www.ibge.gov.br. Acesso em: 06 mar. 2020.

KIMURA, L. M. S. Principais zoonoses. Animais de laboratório: Criação e Experimentação. Rio de Janeiro: Fiocruz, 2012. http://books.scielo.org/id/sfwtj/pdf/andrade-9788575413869-26.pdf. Acesso em: 10 mai. 2018.

LEVINE, G. N. et al. Pet ownership and cardiovascular risk: a scientific statement from the American Heart Association. Circulation, v. 127, n. 23, p. 2353-2363, 2013.

LIMA, A. E. M. A. Teoria do Desenvolvimento Regional e o papel do Estado. Análise Econômica, v. 24, n. 45, 2006. 
MARCONI, M. A.; LAKATOS, E. M. Fundamentos de Metodologia Científica, 8. ed. Atlas, 2017.

MCGEE, J. V.; PRUSAK, L. Gerenciamento estratégico da informação: aumente a competitividade e a eficiência de sua empresa utilizando a informação como uma ferramenta estratégica. 11 ed. Rio de Janeiro: Campus, 2002.

MDR. Site Institucional do Ministério do Desenvolvimento Regional. Codificação Brasileira de Desastres (COBRADE). 2020. https://www.mdr.gov.br/protecao-e-defesa-civil/centro-nacionalde-gerenciamento-de-riscos-e-desastres-cenad/entenda-os-desastres.

MEIRELLES, H. L. Direito administrativo brasileiro. 39 ed. São Paulo: Malheiros, 2013.

MICHEL, M. H. Metodologia e pesquisa cientifica em ciências sociais: um guia prático para acompanhamento da disciplina e elaboração de trabalhos monográficos. 3. ed. São Paulo: Atlas, 2015.

MINTZBERG, H. et al. O processo da estratégia: conceitos, contextos e casos selecionados. 4. ed. Porto Alegre: Bookman, 2014.

MORAIS, R. T. R. Planejamento estratégico: um bem ou mal necessário? Rio de Janeiro: Fundo de Cultura, 2005.

DI NAPOLI, R. B. Animais como pessoas? O lugar dos animais na comunidade moral. Princípios Revista de Filosofia, Natal, v. 20, n. 33, p. 47-78, 2013.

OLIVEIRA, K. D.; ALMEIDA, K. L.; BARBOSA, T. L. Amostragens probabilísticas e não

probabilísticas: técnicas e aplicações na determinação de amostras. Universidade Federal do Espírito Santo. Centro de Ciências Agrárias: Programa de Pós-Graduação em Ciências Florestais; 2013.

PENNISI, E. Where did your dog come from? New tree of breeds may hold the answer. 2017. http://www.sciencemag.org/news/2017/04/where-did-your-dog-come-new-tree-breeds-mayhold-answer. Acesso em: 01 jul. 2018.

PORTAL. Site institucional da Prefeitura Municipal de Curitiba. http://www.curitiba.pr.gov.br /busca/?por=animais\&filtro=4. Acesso em: 07 mar. 2018.

PNDR. Site institucional da Política Nacional de Desenvolvimento Regional. 2020. https://www.mdr.gov.br/

desenvolvimento-regional-e-urbano/politica-nacional-de-desenvolvimento-regional. Acesso em: 2 abr. 2018.

REDE. Site institucional da Rede de Proteção Animal. Disponível em: http://www. protecaoanimal.curitiba.pr.gov.br/Consulta/PesquisaSIC.aspx. Acesso em: 01 fev. 2018.

RDPAC. Rede de Defesa e Proteção Animal da Cidade de Curitiba. Resumo executivo do projeto rede de defesa e proteção animal da cidade de Curitiba. 2009.

<http://www.protecaoanimal.curitiba.pr.gov.br/Publicacoes/Resumo-Plano-Municipal-DefesaProtecao-Animal.pdf. Acesso em: 12 abr. 2017.

REZENDE, D. A. Planejamento de estratégias e informações municipais para cidade digital: guia para projetos em prefeituras e organizações públicas. São Paulo: Atlas, 2012.

REZENDE, D. A. Planejamento estratégico público ou privado: guia para projetos em organizações de governo ou de negócios. São Paulo: Atlas, 2011. 
REZENDE, D. A.; CASTOR, B. V. J. Planejamento estratégico municipal: empreendedorismo participativo nas cidades, prefeituras e organizações públicas. 2. ed. Rio de Janeiro: Brasport, 2006.

REZENDE, D. A.; GUAGLIARDI, J. A. Sistemas de Informação e de Conhecimentos para contribuir na gestão municipal. Revista Produto \& Produção, v. 8, n. 3, p. 45-61, 2005. SANT'ANNA, A.; OLIVEIRA, G. B. Os atores locais como promotores de Desenvolvimento Territorial Endógeno. Colóquio (Faccat), v. 16, n. 3, 2019.

SAMPIERI, R. H.; COLLADO, C. F.; LUCIO, M. del P. B. Metodologia da pesquisa. 5. ed. São Paulo: Penso, 2013.

SOUZA, A. Direitos dos animais domésticos: análise comparativa dos estatutos de proteção. Rev. Direito Econ. Socioambiental, Curitiba, v. 5, n. 1, p. 110-132, 2014.

WANG, G. D. et al. Out of southern East Asia: the natural history of domestic dogs across the world. Cell Research, 26, p. 21-33, 2015.

WSPA. Site institucional World Animal Protection. https://www.worldanimalprotection.org. Acesso em: 10 mar. 2018.

WHO. Site institucional World Health Organization. Guidelines for the Dog Population Management. Geneva: WHO/WSPA. 1992.

YIN, R. K. Estudo de caso: planejamento e métodos. Bookman: Porto Alegre. 2015. 